\title{
Avaliação nutricional, durante a amamentação, de tourinhos em pastejo recebendo suplementação proteica da amamentação à terminação ${ }^{1}$
}

\author{
Henrique Jorge Fernandes ${ }^{2,3}$, Mário Fonseca Paulino ${ }^{3}$, Edenio Detmann ${ }^{3}$, Sebastião de \\ Campos Valadares Filho ${ }^{3}$, Aline Gomes da Silva ${ }^{3}$, Marlos Oliveira Porto ${ }^{3}$, Anilza Andréia da \\ Rocha $^{3}$, Gabriel Figueiredo Biancardi ${ }^{3}$
}

1 Projeto parcialmente financiado pela FAPEMIG e pelo CNPq.

2 Universidade Estadual de Mato Grosso do Sul, UEMS/Unidade de Aquidauana. Bolsista FUNDECT/MS.

${ }^{3}$ Departamento de Zootecnia - Universidade Federal de Viçosa.

RESUMO - O objetivo neste estudo foi avaliar as condições nutricionais de tourinhos em aleitamento, a pasto, recebendo suplementação com concentrados proteicos durante a época de transição águas-seca. Foram utilizados 52 bezerros mestiços com idade média inicial de 130 dias. Os animais foram distribuídos em quatro lotes, alojados em piquetes de Brachiaria decumbens Stapf junto com suas mães, onde receberam uma das quatro estratégias de suplementação: três suplementos concentrados, ou sal mineral (controle). Os suplementos concentrados diferiram quanto ao nível de proteína. Após 45 dias, realizou-se a avaliação nutricional dos animais, que incluiu a estimação do consumo e da digestão de nutrientes e das características do metabolismo proteico. A estimação do consumo e da digestibilidade foi feita utilizando-se os indicadores: LIPE $^{\circledR}$, dióxido de titânio e fibra em detergente neutro indigestível. Realizou-se ainda coleta de amostras de urina e de sangue O efeito de suplementação e os efeitos linear e quadrático do nível de proteína no concentrado foram avaliados pela decomposição da soma de quadrados em contrastes ortogonais, adotando-se $\alpha=0,10$. O consumo de concentrado substituiu parte do pasto ingerido pelos bezerros e aumentou a ingestão de proteína, a digestibilidade da matéria seca e matéria orgânica, o teor de nutrientes digestíveis totais e a excreção de nitrogênio na urina. O nível de proteína no suplemento tem efeito linear positivo sobre a ingestão diária de proteína, a digestibilidade de todos os nutrientes e o teor de nutrientes digestíveis totais e efeito quadrático sobre a excreção de nitrogênio na forma de ureia na urina.

Palavras-chave: bezerros, consumo, digestibilidade, gado de corte

\section{Nutritional evaluation, during the nursing phase, of grazing young bulls that received supplementation with different protein profiles from nursing to finishing}

ABSTRACT - The objective of this study was to evaluate the nutritional status of grazing nursing young bulls supplemented with concentrates with different protein levels during the rainy-dry season transition. Fifty two crossbred Nellore calves with initial mean age of 130 days were divided into four lots, housed in paddocks of Brachiaria decumbens Stapf and received one of the four different supplementation strategies: three different concentrate supplements, or mineral salt (control). The levels of protein in the concentrate supplements varied. After 45 days, the nutritional evaluation of animals, which included the prediction of intake and digestion of nutrients and characteristics of protein metabolism, was made. The prediction of intake and digestibility used the indicators LIPE $^{\circledR}$, titanium dioxide and neutral detergent fiber indigestible. Urine and blood samples were collected too. The supplementation effect, and the linear and quadratic effects of the level of protein in the concentrate were evaluated by the decomposition of the sum of squares into orthogonal contrasts, adopting $\alpha=0.10$. The concentrate intake replaced part of the pasture ingested by the calves and increased protein intake, the digestibility of dry and organic matter, the total digestible nutrients content, and the nitrogen excretion in urine. The level of protein in the supplement has a positive linear effect on the daily protein intake, the digestibility of all nutrients and the total digestible nutrients content, and quadratic effect on the excretion of nitrogen as urea in the urine.

Key Words: beef cattle, calves, digestibility, intake

Recebido em 19/5/2010 e aprovado em 1/6/2011. 


\section{Introdução}

Os sistemas de produção de carne bovina no Brasil utilizam as pastagens como substrato básico (Paulino et al., 2003), por isso a produção de carne depende da sazonalidade da produção das forrageiras.

A prática de suplementação a bovinos em pastagens ainda é incapaz de maximizar e garantir a estabilidade da produção animal nestas condições. A falta de informações sobre as bases nutricionais envolvidas na resposta à suplementação a pasto tem limitado a aplicação desses resultados nos sistemas comerciais.

Ainda que o aumento da produção de leite permitisse aumentar o peso à desmama dos bezerros, o nível nutricional das matrizes, na maior parte dos sistemas de produção, é limitante para suportar níveis elevados de produção de leite.

O creep-feeding pode possibilitar melhor ganho de peso, maior peso corporal e melhor desenvolvimento do sistema digestivo dos animais à desmama.

Brito \& Sampaio (2001) sugeriram que a proteína ingerida permanece abaixo do requerimento do bezerro durante toda a lactação. Assim, a suplementação proteica nesta fase tende a equilibrar a dieta, permitindo ainda aos animais obter mais energia de cada unidade de forragem ingerida.

Objetivou-se com este trabalho avaliar as características nutricionais de bezerros na fase de aleitamento, durante a época de transição águas-seca do ano, recebendo suplementação com concentrados com diferentes níveis proteicos.

\section{Material e Métodos}

O experimento foi conduzido no Setor de Bovinocultura de Corte da Universidade Federal de Viçosa, no período de março a junho de 2007, em um total de 112 dias. Foram utilizados 52 bezerros mestiços com, no mínimo, 50\% de sangue nelore, machos, com idade média inicial de $130 \pm$ 30,1 dias, todos amamentados por suas respectivas mães.

O controle de endoparasitas foi realizado no início do experimento e, sempre que necessário, com dosificações estratégicas de vermífugos de amplo espectro e o de ectoparasitas (carrapatos, bernes e miíases) com produtos específicos para os controles.

Após a pesagem inicial, para cada animal foi designada aleatoriamente uma das quatro estratégias de suplementação nutricional avaliadas: um dos três suplementos concentrados com diferentes níveis proteicos (Tabela 1), ou mistura mineral. Os animais sob suplementação concentrada recebiam nesta fase da vida suplementos na proporção de $1,2 \mathrm{~kg} / \mathrm{animal} / \mathrm{dia}$, enquanto os do grupo controle recebiam suplemento mineral à vontade (controle).

Os suplementos concentrados foram formulados de forma a atender às exigências nutricionais dos animais, prevista no NRC (2000) e às características específicas do pasto naquela época do ano. Os animais que recebiam uma mesma estratégia de suplementação foram agrupados em lotes, que foram então alojados em piquetes formados com Brachiaria decumbens Stapf junto com suas mães. A cada sete dias, os lotes foram rotacionados entre os piquetes, visando à eliminação de possíveis diferenças entre os piquetes.

Durante toda a fase de amamentação, as vacas tiveram acesso a suplementações de macro e microelementos minerais, em comedouro de madeira coberto de 2 metros de comprimento. Os comedouros eram duplos, com acesso de um lado para as vacas e do outro lado para os bezerros, colocado mais baixo que o cocho das vacas e cercado com cerca de madeira para o oferecimento seletivo da

Tabela 1 - Composição dos suplementos concentrados, do pasto e do leite consumidos pelos animais

\begin{tabular}{|c|c|c|c|c|c|}
\hline \multirow[t]{2}{*}{ Item } & \multicolumn{3}{|c|}{ Suplementos } & \multirow[t]{2}{*}{ Pasto $^{1}$} & \multirow[t]{2}{*}{ Leite } \\
\hline & Alta proteína & Média proteína & Baixa proteína & & \\
\hline \multicolumn{6}{|c|}{ Combinação de alimentos (\% matéria natural) } \\
\hline Farelo soja & 64,9 & 32,5 & 0,00 & & \\
\hline Suplemento mineral & 2,60 & 2,60 & 2,60 & & \\
\hline \multicolumn{6}{|c|}{ Composição química ${ }^{2}$} \\
\hline Proteína bruta & 31,8 & 24,8 & 9,42 & 13,9 & 25,8 \\
\hline Nitrogênio não-proteico & 34,7 & 25,4 & 20,8 & 18,6 & n.a. \\
\hline Fibra em detergente neutro ${ }^{3}$ & 20,3 & 21,4 & 6,50 & 54,4 & 0,00 \\
\hline Fibra em detergente neutro indigestível & 1,09 & 1,45 & 1,32 & 16,5 & 0,00 \\
\hline Extrato etéreo & 1,83 & 2,45 & 2,84 & 1,46 & 34,2 \\
\hline
\end{tabular}

n.a. - não-avaliado.

${ }_{1}^{1}$ Obtido por meio de simulação manual de pastejo.

2 Expresso como \% MS, exceto matéria seca (expressa como \% MN) e nitrogênio não-proteico (expresso como \% PB).

${ }^{3}$ Fibra em detergente neutro corrigida para cinzas e proteína. 
suplementação (concentrada ou mineral) para os mesmos (creep feeding).

No início e no final desta fase de vida e a cada 28 dias, os bezerros foram pesados após jejum de sólidos de 16 horas para acompanhamento de seu crescimento.

O ganho médio diário de toda a fase de amamentação foi calculado como a diferença entre os pesos iniciais e finais divididos pelos 112 dias do experimento. O ganho médio diário durante a avaliação nutricional foi calculado pela diferença entre os pesos tomados aos 28 e aos 56 dias deste experimento, dividida pelo período de 28 dias.

Após 45 dias de experimento, conduziu-se o ensaio para avaliação nutricional dos animais. Esta avaliação incluiu a estimação de consumo e digestão e estimação de características do metabolismo proteico dos animais experimentais. A estimação do consumo pelos animais foi realizada por intermédio da técnica dos indicadores. Empregou-se o LIPE ${ }^{\circledR}$ como indicador para estimação da excreção fecal (Rodríguez et al., 2006), o dióxido de titânio como indicador do consumo de suplemento (Kincheloe, 2004) e a fibra em detergente neutro indigestível (FDNi) como indicador interno para estimação direta do consumo de pasto e indireta da digestibilidade da dieta.

No período do ensaio, durante os nove primeiros dias, o dióxido de titânio foi adicionado ao suplemento concentrado, na proporção de $1 \%$, conforme sugestão de Kincheloe (2004). Nos dias 7, 8 e 9, procedeu-se à aplicação nos bezerros, via sonda esofágica, de cápsulas de $500 \mathrm{mg}$ de LIPE ${ }^{\circledR}$. Entre o $8^{\circ}$ e $10^{\circ}$ dias, procedeu-se à coleta de amostras de fezes, por defecação espontânea ou diretamente no reto dos animais, uma vez por dia, às 16 h, 12 h e 8 h, respectivamente. As amostras fecais foram acondicionadas em sacos plásticos, identificadas e congeladas a $-20{ }^{\circ} \mathrm{C}$.

No $11^{\circ}$ dia do ensaio, foi realizada a coleta nos animais de amostras spot de urina (10 mL), em micção espontânea e de sangue, realizadas aproximadamente quatro horas após o fornecimento do suplemento. Após a coleta, as amostras de urina foram diluídas em $40 \mathrm{~mL}$ de $\mathrm{H}_{2} \mathrm{SO}_{4}(0,036 \mathrm{~N})$ e congeladas a $-20^{\circ} \mathrm{C}$ para posterior determinação dos teores de creatinina e ureia, segundo Valadares et al. (1999). As amostras de sangue foram coletadas imediatamente após a coleta de urina utilizando-se tubos de vacuntainer, sendo as amostras imediatamente centrifugadas e o soro congelado para posterior avaliação de ureia sérica.

A cada mês do experimento, procedeu-se à avaliação quantitativa e qualitativa do pasto. Foi realizada coleta de amostra da forragem pelo corte rente ao solo de cinco áreas delimitadas por um quadrado metálico de $0,5 \times 0,5 \mathrm{~m}$, escolhidas aleatoriamente em cada piquete experimental (McMeniman, 1997), em um total de 20 amostras.
Após a coleta, as amostras foram pesadas e homogeneizadas e, a partir desta amostra homogênea, foram retiradas duas amostras compostas: uma para avaliação da disponibilidade total de MS e outra para análise das disponibilidades de MS de folha verde, folha seca, colmo verde e colmo seco em cada piquete experimental. No dia imediatamente após o ensaio de avaliação nutricional, realizou-se amostragem qualitativa do pasto consumido pelos animais via simulação manual de pastejo.

Dois dias após o ensaio, realizou-se coleta de leite das vacas para estimação da produção e composição do mesmo. As amostras foram coletadas em sete vacas de cada grupo, escolhidas aleatoriamente. Antes da estimação da produção de leite, os bezerros foram separados das mães às $18 \mathrm{~h}$ do dia anterior e mantidos assim, em curral com acesso à água, até as 6 h do dia seguinte. As vacas foram mantidas em pasto próximo, e, a partir das 6 h, submetidas à esgota, através de ordenha manual, com aplicação de oxitocina. A produção diária de leite de cada vaca foi estimada como a produção do período (considerando-se a hora da separação dos bezerros e a hora de ordenha de cada vaca), ajustada para 24 horas, como proposto por Restle et al. (2003).

Após a pesagem, foram retiradas amostras de leite para análise, as quais foram enviadas para o laboratório de qualidade do leite da EMBRAPA - Gado de Leite para quantificação dos teores de sólidos totais, proteína, gordura e lactose.

As amostras de fezes, depois de secas em estufa com ventilação forçada $\left(60^{\circ} \mathrm{C} / 72 \mathrm{~h}\right)$ e processadas em moinho com peneira de $1 \mathrm{~mm}$, foram compostas, com base no peso seco ao ar, por animal. As amostras de pasto foram secas e moídas do mesmo modo. As análises de MS, MO, PB e extrato etéreo (EE) dos suplementos concentrados, do pasto e das fezes foram realizadas de acordo com as técnicas descritas por Silva \& Queiroz (2002). O conteúdo de nitrogênio não-proteico foi determinado utilizando-se o método do ácido tri-cloro-acético (Licitra et al., 1996). A quantificação dos teores de FDN seguiu os métodos de Van Soest \& Robertson (1985).

As amostras de suplemento, forragem e fezes foram quantificadas quanto aos teores de FDNi segundo método descrito por Cochran et al. (1986). Adotou-se, no entanto, incubação ruminal in situ por 240 horas, como sugerido por Casali et al. (2008). A excreção fecal foi, então, estimada segundo a metodologia proposta por Rodríguez et al. (2006).

O consumo de matéria seca de suplemento ( $\mathrm{kg} / \mathrm{dia})$ foi estimado segundo a Equação [1].

$C S U P=\frac{E F \times C F t i}{C S t i}$ Eq. [1] 
em que: CSUP = consumo de matéria seca de suplemento (kg/dia); EF = excreção fecal (kg/dia); CFti = concentração fecal de titânio (kg/kg); CSti = concentração de titânio no suplemento $(0,01 \mathrm{~kg} / \mathrm{kg})$.

As estimativas do consumo voluntário foram obtidas segundo a Equação [2].

$C M S=\frac{[(E F \times F z)-(C S U P \times S p)]}{P S}+C S U P+C L$

em que: $\mathrm{CMS}=$ consumo de matéria seca $(\mathrm{kg} / \mathrm{dia})$; $\mathrm{EF}$ = excreção fecal (kg/dia); Fz = concentração de FDNi nas fezes $(\mathrm{kg} / \mathrm{kg})$; CSUP = consumo de matéria seca de suplementos (kg/dia); Sp = concentração de FDNi no suplemento (kg/kg); Ps = concentração de FDNi na forragem $(\mathrm{kg} / \mathrm{kg})$; e CL = consumo de matéria seca de leite ( $\mathrm{kg} / \mathrm{dia})$.

Os consumos de nutrientes foram obtidos a partir das estimativas de consumo e da composição das amostras de pasto, de suplementos, de leite e das fezes, segundo os métodos descritos anteriormente.

O coeficiente de substituição do pasto pelo concentrado foi calculado como a diferença entre o consumo de pasto do grupo controle e de cada grupo suplementado, dividido pelo consumo de concentrado (g pasto/g de concentrado ingerido).

A relação volumoso: concentrado foi calculada como a proporção que o consumo de MS de pasto e o consumo de MS de suplemento concentrado representavam, respectivamente, da soma do consumo de MS de pasto e concentrado de cada animal.

Os coeficientes de digestibilidade aparente de cada nutriente foram calculados segundo a Equação [3].

$C D n u t=\frac{[(C F O R \times C F n u t)+(C S U P \times C S n u t)+(C L E I \times C L n u t)-(E F \times C F n u t)]}{[(C F O R \times C F n u t)+(C S U P \times C S n u t)+(C L E I \times C L n u t)]}$

em que: CDNut $=$ coeficiente de digestibilidade aparente do nutriente (\%); CFOR = consumo de forragem ( $\mathrm{kg} / \mathrm{dia})$; CFnut $=$ concentração do nutriente na forragem (\%); CSUP = consumo de suplemento $(\mathrm{kg} / \mathrm{dia}) ;$ CSnut = concentração do nutriente no suplemento (\%); CLEI = consumo de leite ( $\mathrm{kg} / \mathrm{dia})$; CLnut = concentração do nutriente no leite (\%); EF = excreção fecal (kg/dia); CFnut = concentração do nutriente nas fezes (\%).

O calculo de NDT da dieta foi realizado considerandose o teor de nutrientes digestíveis, segundo a Equação [4]:

$$
\mathrm{NDT}=\mathrm{PBd}+2,25 \times \mathrm{EEd}+\mathrm{FDNd}+\mathrm{CNFd} \quad \text { Eq. [4] }
$$

em que: $\mathrm{NDT}$ = nutrientes digestíveis totais (\% MS); PBd = proteína bruta digestível (\% MS); EEd = extrato etéreo digestível (\%MS); FDNd = fibra em detergente neutro digestível (\%MS); CNFd = carboidratos não-fibrosos digestíveis (\%MS).
Foram utilizados kits comerciais para a estimação dos teores de creatinina e ureia nas amostras de urina. O total de proteína excretada na urina foi determinada pelo método Kjeldahl, segundo Silva \& Queiroz (2002). A síntese de proteína microbiana foi estimada através das amostras de urina. Estas foram analisadas para os derivados de purinas (alantoína e ácido úrico), por intermédio do método colorimétrico, segundo técnica de Fujihara et al. (1987) descrita por Chen \& Gomes (1992).

O volume urinário foi obtido pela relação entre a excreção diária de creatinina, adotando-se a equação descrita por Chizotti et al. (2004) e a concentração de creatinina nas amostras coletadas.

As purinas microbianas absorvidas ( $\mathrm{Ymmol} / \mathrm{dia}$ ) foram calculadas a partir da excreção de derivados de purinas na urina (X mmol/dia) por meio da equação:

$Y=\frac{X-0,385 \times P C^{0,75}}{0.85}$

em que: $0,85=$ recuperação de purinas absorvidas como derivados urinários de purinas; 0,385 = contribuição endógena para a excreção de purinas (Verbic et al., 1990).

A síntese ruminal de compostos nitrogenados (Y,g N/dia) foi calculada em função das purinas absorvidas (P, mmol/dia), pela equação de Chen \& Gomes (1992), Eq. [6].

$Y=\frac{70 \times P}{(0,83 \times 0.116 \times 1000)}$

em que: 70 é o conteúdo de $\mathrm{N}$ de purinas (mg N/mol); 0,116 a relação $\mathrm{N}$ purina: $\mathrm{N}$ total nas bactérias; e 0,83 a digestibilidade das purinas microbianas.

Estimou-se então a eficiência de síntese de PBmic segundo a Eq. [7].

PBmic $=($ Nmic $\times 6,25) /$ IDNDT em que: $\mathrm{PBmic}=$ eficiência de produção de $\mathrm{PB}$ microbiana (g/kg NDT); Nmic = produção diária de nitrogênio microbiano (g/dia); IDNDT = ingestão diária de NDT (kg/dia).

O efeito de suplementação e os efeitos lineares e quadráticos do nível de proteína no suplemento sobre o consumo, a digestibilidade e as características do metabolismo proteico dos animais foram avaliados por decomposição da soma de quadrados de tratamentos por meio de contrastes ortogonais (Steel et al., 1997). Utilizou-se o PROC GLM do SAS (Statystical Analysis System, versão 9.2). Para todos os procedimentos estatísticos, adotou-se $\alpha=0,10$.

\section{Resultados e Discussão}

Os dados de peso e ganho de peso dos animais (Tabela 2) foram apresentados como indicativos do tipo de animal e do 
Tabela 2 - Pesos corporais iniciais e finais e ganho médio diário dos animais durante a fase de amamentação e peso corporal médio e ganho médio diário durante o período de ensaio de avaliação nutricional

\begin{tabular}{lcccc}
\hline Item & \multicolumn{3}{c}{ Suplementos } \\
\cline { 2 - 5 } & Controle & $\begin{array}{c}\text { Concentrado de } \\
\text { alta proteína }\end{array}$ & $\begin{array}{c}\text { Concentrado de } \\
\text { média }\end{array}$ & $\begin{array}{c}\text { Concentrado de } \\
\text { proteína } \\
\text { baixa proteína }\end{array}$ \\
\hline Peso corporal inicial & $130 \pm 29,8$ & $128 \pm 28,8$ & $127 \pm 28,8$ & $131 \pm 28,6$ \\
Peso corporal final & $200 \pm 25,2$ & $213 \pm 36,4$ & $218 \pm 31,4$ & $203 \pm 34,4$ \\
Ganho médio diário da fase de amamentação & $0,620 \pm 0,161$ & $0,737 \pm 0,151$ & $0,800 \pm 0,154$ & $0,680 \pm 0,108$ \\
Peso corporal no período de avaliação & $172 \pm 24,9$ & $178 \pm 33,5$ & $181 \pm 30,3$ & $172 \pm 34,0$ \\
Ganho médio diário no período de avaliação & $0,633 \pm 0,219$ & $0,628 \pm 0,137$ & $0,890 \pm 0,289$ & $0,863 \pm 0,205$ \\
\hline
\end{tabular}

seu estado fisiológico durante esta fase de vida e durante o período de avaliação nutricional.

O experimento foi realizado entre os meses de março e junho de 2007, incluindo o fim do período das águas e o período de transição águas-seca daquele ano. Os dados comprovam disponibilidade de matéria seca total do pasto uniforme durante os três primeiros meses (de março a maio), com valores em torno de $4.500 \mathrm{~kg}$ MS/ha (Figura 1). Segundo Euclides et al. (1992), essa disponibilidade seria suficiente para se manter um desempenho ótimo para bovinos de corte em condições do Brasil Central. Por outro lado, a disponibilidade de cerca de $3.000 \mathrm{~kg} \mathrm{MS} / \mathrm{ha}$ observada em junho, segundo este parâmetro, indicaria possível redução no desempenho dos animais a partir deste mês.

Observou-se aumento contínuo da participação de materiais secos na composição da massa forrageira, paralelamente à redução da disponibilidade de folhas e caules verdes à medida que o experimento avançava. $\mathrm{O}$ aumento da participação de material seco foi maior nos caules, provavelmente devido ao consumo preferencial de folhas pelos animais, diminuindo a quantidade de folhas disponíveis para senescência.

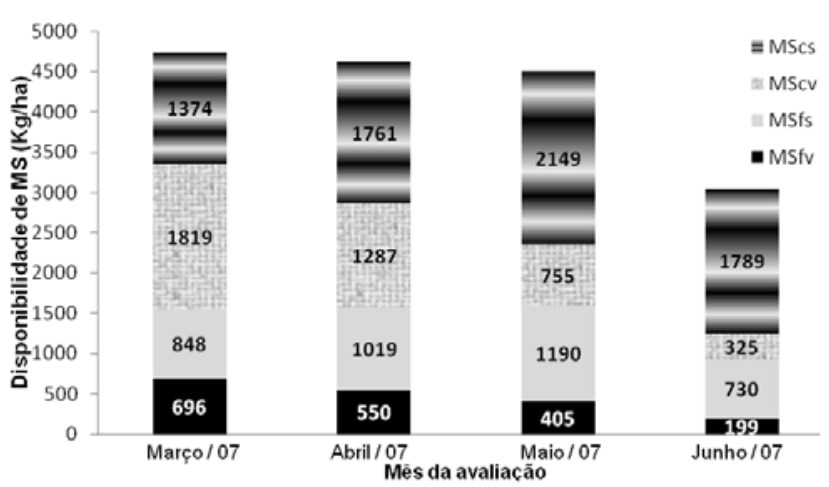

Figura 1 - Disponibilidade de matéria seca total do pasto e de seus componentes (folhas verdes (MSfv), folhas seca (MSfs), caules verdes (MScv) e caules secos (MScs)) durante o experimento.
No mês de junho, paralelamente à redução da disponibilidade de MS total do pasto, observou-se intensificação neste processo de "substituição" de material verde por material seco.

Não houve efeito significativo $(\mathrm{P}>0,10)$ da suplementação concentrada, nem do nível de PB no suplemento concentrado sobre o consumo de MS (Tabela 3).

A decomposição desta ingestão diária de MS em seus componentes mostrou, no entanto, resultados importantes. A avaliação da ingestão diária de MS de leite confirmou que a produção de leite das mães foi semelhante entre os grupos sob suplementação, o que não ocasionou diferença de desempenho dos grupos de animais. Também o consumo de suplemento concentrado não foi diferente nos grupos que o recebiam $(P>0,10)$, sendo em média de $0,996 \mathrm{~kg} /$ dia. Este consumo representou cerca de $0,563 \%$ do peso corporal médio dos animais sob suplementação durante o ensaio de avaliação nutricional.

A ingestão de MS de pasto, apesar de não ter sido afetada pelo nível de proteína dos concentrados ( $\mathrm{P}>0,10)$, foi menor $(P<0,01)$ nos animais sob suplementação. A manutenção de um mesmo nível de ingestão diária de MS total e a redução dessa ingestão de MS do pasto pelos animais evidenciam a ocorrência de efeito substitutivo do consumo de pasto por concentrado. Neste caso, a substituição média foi de cerca de $0,78 \mathrm{~g}$ de consumo de pasto por g de concentrado ingerido (Tabela 3) e isso comprova que cerca de $78 \%$ do consumo de concentrado foi compensado pela redução no consumo de pasto dos animais.

Zin \& Garces (2006) explicam que, a partir de um fornecimento de concentrado em níveis correspondentes a $0,3 \%$ do peso corporal, ocorre redução no consumo de forragem. Segundo esses autores, este processo seria intensificado somente a partir do fornecimento de $0,8 \%$ do peso corporal. $\mathrm{O}$ alto nível de redução na ingestão de pasto para o consumo de $0,563 \%$ do peso corporal de concentrado aqui observado parece ser além do predito por esses autores.

Acompanhando o comportamento do consumo de MS, também a ingestão diária de MO não foi afetada 
Tabela 3 - Características ingestivas dos animais dos grupos experimentais

\begin{tabular}{|c|c|c|c|c|c|c|c|c|}
\hline \multirow[t]{2}{*}{ Ingestão diária } & \multicolumn{4}{|c|}{ Suplementos } & \multirow[b]{2}{*}{$\begin{array}{l}\text { CV } \\
(\%)\end{array}$} & \multicolumn{3}{|c|}{ Valor-P } \\
\hline & Controle & \multicolumn{3}{|c|}{$\begin{array}{l}\text { Nível de proteína } \\
\text { no concentrado }\end{array}$} & & $\begin{array}{c}\text { Efeito da } \\
\text { suplementação } \\
\text { concentrada }\end{array}$ & $\begin{array}{l}\text { Efeito linear } \\
\text { do nível } \\
\text { de proteína }\end{array}$ & $\begin{array}{c}\text { Efeito } \\
\text { quadrático do nível } \\
\text { de proteína }\end{array}$ \\
\hline & & & & & $\mathrm{kg} / \mathrm{dia}$ & & & \\
\hline Matéria seca total & 3,425 & 3,477 & 3,804 & 3,857 & 18,3 & 0,1999 & 0,1625 & 0,5528 \\
\hline Matéria seca da pastagem & 2,721 & 1,923 & 1,957 & 1,951 & 30,6 & 0,0008 & 0,9178 & 0,9278 \\
\hline Matéria orgânica & 3,088 & 3,193 & 3,485 & 3,512 & 18,4 & 0,1347 & 0,1992 & 0,5279 \\
\hline Fibra em detergente neutro & 1,575 & 1,168 & 1,367 & 1,343 & 25,9 & 0,0197 & 0,2237 & 0,3621 \\
\hline Proteína bruta total & 0,560 & 0,530 & 0,734 & 0,827 & 19,3 & 0,0023 & $<0,0001$ & 0,1845 \\
\hline Proteína bruta da pastagem & 0,378 & 0,267 & 0,272 & 0,271 & 30,6 & 0,0008 & 0,9200 & 0,9257 \\
\hline Proteína bruta do leite & 0,182 & 0,183 & 0,195 & 0,221 & 21,0 & 0,3630 & 0,2517 & 0,1841 \\
\hline Proteína bruta do concentrado & - & 0,080 & 0,271 & 0,334 & 65,9 & - & 0,0002 & 0,2310 \\
\hline Coeficiente de substituição (g/g) & & & & & g/kg PC & & & \\
\hline Matéria seca total & 20,3 & 20,8 & 21,8 & 22,0 & 23,9 & 0,4454 & 0,5659 & 0,8262 \\
\hline Matéria seca da pastagem & 16,1 & 11,2 & 10,8 & 11,1 & 29,0 & $<0,0001$ & 0,9414 & 0,7729 \\
\hline Fibra em detergente neutro & 9,30 & 6,80 & 7,70 & 7,60 & 26,2 & 0,0073 & 0,3328 & 0,5269 \\
\hline
\end{tabular}

significativamente pela suplementação concentrada, ou pelo nível de PB no concentrado ( $\mathrm{P}>0,10$; Tabela 3 ).

A ingestão diária de FDN, por sua vez, foi afetada pelo fornecimento de concentrado $(\mathrm{P}<0,05$; Tabela 3$)$. Os animais que recebiam apenas suplemento mineral consumiram mais FDN que aqueles que recebiam suplementação concentrada. Isso está relacionado ao maior consumo de MS de pasto por estes animais. Como este pasto consumido a mais foi substituído pelo concentrado na dieta dos animais sob suplementação, a diferença de consumo de FDN reflete a diferença do teor de FDN entre o pasto e o concentrado multiplicada por esta substituição. Bürguer et al. (2000) também observaram que o aumento do nível de concentrado em uma dieta tende a reduzir a ingestão de FDN pelos animais.

O principal fator da maior ingestão diária de $\mathrm{PB}$ dos animais sob suplementação com concentrados $(P<0,01$, Tabela 3) foi a proteína oriunda dos suplementos concentrados. Apesar de os animais que só recebiam suplemento mineral terem ingerido cerca de $100 \mathrm{~g}$ de proteína do pasto por dia a mais que os suplementados com concentrados, a ingestão de PB do concentrado dos animais sob suplementação com concentrado com alta e média proteína mais que compensou esta proteína. Por outro lado, a ingestão de PB dos animais sob suplementação com baixa proteína acabou sendo bastante semelhante à dos animais controle, devido à baixa ingestão de $\mathrm{PB}$ oriunda do concentrado deste grupo de animais. Brito et al. (2002) também observaram maior consumo de PB quando forneceram concentrado com maior teor deste nutriente a bezerros em lactação.

Os consumos de PB pelos animais sob suplementação foram cerca de $110 \mathrm{~g}$ a menos que os $0,810 \mathrm{~kg} /$ dia de $\mathrm{PB}$ sugeridos pelo NRC (2000) como exigência para animais com pesos e ganhos de peso corporais semelhantes. A ingestão de PB do grupo controle, por sua vez, ficou cerca de 150 g abaixo da exigência de $0,707 \mathrm{~kg} /$ dia predita pelo NRC (2000). Necessidades de proteína cerca de 15 a 20\% abaixo das exigências preditas pelo NRC (2000) também foram observadas por Freitas et al. (2006) considerando dados próprios e de 14 trabalhos da literatura brasileira.

A ingestão diária de NDT aumentou com o fornecimento de concentrado $(\mathrm{P}<0,05)$, mas não foi afetada pelos níveis de proteína bruta neste suplemento $(\mathrm{P}>0,10)$. A substituição de parte da forragem consumida pelo concentrado, como já discutido, pode explicar boa parte desses resultados. A maior concentração energética do suplemento concentrado em relação ao pasto que deixou de ser consumido levou à maior ingestão de energia (aqui medida na forma de NDT), mesmo com consumo de MS similares entre os grupos controle e com suplementação.

O consumo médio de 2,803 kg NDT/animal/dia observado nos animais dos grupos sob suplementação foi cerca de $400 \mathrm{~g}$ (12,5\%) inferior à exigência predita pelo NRC (2000) para animais com peso e desempenho semelhantes. Os animais do grupo controle, por outro lado, ingeriram em média 383 g NDT/animal/dia a menos que os 2,770 kg estimados pelo NRC (2000). Esse valor representa ingestão 
cerca de $16 \%$ abaixo das predições daquele sistema. Esta menor exigência nutricional de energia é coerente com diversos trabalhos realizados em condições brasileiras (Silva et al., 2002; Freitas et al., 2006).

Observaram-se pequenas variações, apenas numéricas ( $\mathrm{P}>0,10)$, na relação volumoso:concentrado consumida pelos animais que receberam os suplementos. Devido aos pesos corporais bastante semelhantes dos animais, a expressão do consumo de MS como g/kg PC não evidenciou nenhuma diferença em relação aos resultados da análise de consumo de MS expresso como kg/dia. Nenhum efeito de suplementação ou de nível de proteína no suplemento sobre o consumo de MS $(\mathrm{P}>0,10)$ foi observado. Ao contrário do observado neste estudo, Brito et al. (2002) notaram consumo de MS cerca de $17 \%$ superior quando utilizado um concentrado com maior teor de PB na suplementação de bezerros durante a amamentação.

Também o consumo de MS oriunda de pastagem e o consumo de FDN, expressos como g/kg PC, comprovaram o mesmo efeito de suplementação $(\mathrm{P}<0,01)$ evidenciado no estudo destas características expressas como kg/dia. Essas características também não sofreram efeito significativo ( $\mathrm{P}>0,10)$ do nível de proteína no suplemento.

Os baixos consumos de FDN observados podem ser explicados pela fase de vida dos animais. Como cerca de 20\% da MS ingerida pelos animais provinha do leite materno, e este leite não possui FDN, era de se esperar que o consumo de FDN fosse menor que o normalmente observado em animais a pasto. Essa presença do leite materno na dieta dos animais atua ainda causando menor desenvolvimento ruminal, o que também reduz a capacidade de consumo de pasto destes animais.

Ribeiro et al. (2001), trabalhando com animais tão jovens quantos os aqui avaliados, também observaram baixo consumo de FDN para animais em fase de crescimento. Esses autores destacaram que, nestes casos, a limitação de consumo dos animais poderia ser ainda decorrente da saciedade energética.
Os coeficientes de digestibilidade da MS e da MO foram afetados $(\mathrm{P}<0,01)$ pelo fornecimento de suplemento concentrado (Tabela 4). O aumento da digestibilidade desses componentes (cerca de 5 pontos percentuais) representa melhoria de cerca de $7 \%$ na capacidade do animal de retirar nutrientes dos alimentos. Essa melhoria pode ser associada à substituição de pasto pelo concentrado na MS ingerida dos animais suplementados.

Zamperlini (2008) destacou o maior desenvolvimento ruminal de animais sob suplementação com concentrados, o que pode levar a um possível aumento na capacidade de digestão do pasto por esses animais.

$O$ coeficiente de digestibilidade da PB sofreu efeito significativo $(\mathrm{P}>0,01)$ da suplementação. As pequenas diferenças absolutas na digestibilidade da PB da dieta como um todo, no entanto, podem ser explicadas pela época do ano e pelo alto teor de PB no pasto. Neste caso, a digestibilidade da $\mathrm{PB}$ do pasto pode ter assumido valores próximos ao do concentrado, causando esse efeito.

Os coeficientes de digestibilidade da MS, MO, PB e FDN sofreram aumento significativo $(\mathrm{P}<0,05)$ à medida que se aumentou o nível de PB. É interessante notar que, enquanto os coeficientes de digestibilidade da MS, MO e PB apresentaram aumento relativamente uniforme decorrente da elevação no teor de PB no suplemento, a digestibilidade da FDN é menor quando os animais recebem concentrado com baixa proteína, tornando-se constante com o uso de concentrados com maiores teores de proteína.

Uma possível explicação para este fenômeno poderia estar ligada à acidificação do rúmen dos animais que recebiam o suplemento concentrado com baixa proteína. Como os animais eram jovens, seus rúmens ainda estavam em desenvolvimento, por isso, estavam mais susceptíveis a distúrbios digestivos. O suplemento concentrado de baixa proteína fornecido aos animais era composto basicamente de milho, que possui altos teores de amido. Apesar de as quantidades fornecidas diariamente não serem altas, devido à susceptibilidade ruminal, esta

Tabela 4 - Coeficientes de digestibilidade aparente total (\%) e teores de nutrientes digestíveis totais (NDT) das dietas

\begin{tabular}{|c|c|c|c|c|c|c|c|c|}
\hline & \multicolumn{4}{|c|}{ Suplementos } & \multirow{3}{*}{$\begin{array}{l}\mathrm{CV} \\
(\%)\end{array}$} & \multicolumn{3}{|c|}{ Valor-P } \\
\hline & \multirow[t]{2}{*}{ Controle } & \multicolumn{3}{|c|}{$\begin{array}{l}\text { Nível de proteína } \\
\text { no concentrado }\end{array}$} & & \multirow{2}{*}{$\begin{array}{c}\text { Efeito da } \\
\text { suplementação } \\
\text { concentrada }\end{array}$} & \multirow{2}{*}{$\begin{array}{c}\text { Efeito linear } \\
\text { do nível } \\
\text { de proteína }\end{array}$} & \multirow{2}{*}{$\begin{array}{c}\text { Efeito } \\
\text { quadrático doníve } \\
\text { de proteína }\end{array}$} \\
\hline & & Baixo & Médio & Alto & & & & \\
\hline Matéria seca & 63,4 & 65,6 & 68,2 & 70,6 & 5,72 & 0,0006 & 0,0019 & 0,9653 \\
\hline Matéria orgânica & 66,1 & 67,9 & 71,1 & 73,5 & 5,16 & 0,0002 & 0,0004 & 0,7797 \\
\hline Proteína bruta & 77,5 & 79,3 & 80,5 & 84,2 & 3,95 & 0,0006 & 0,0004 & 0,2848 \\
\hline Fibra em detergente neutro & 65,5 & 65,3 & 70,1 & 70,0 & 7,28 & 0,0728 & 0,0230 & 0,1597 \\
\hline Extrato etéreo & 78,3 & 79,5 & 82,5 & 83,5 & 4,14 & 0,0083 & 0,0164 & 0,4201 \\
\hline Carboidratos não-fibrosos & 63,6 & 71,4 & 70,2 & 72,4 & 7,38 & 0,0003 & 0,7025 & 0,3817 \\
\hline Nutrientes digestíveis totais & 67,4 & 72,6 & 74,0 & 75,9 & 3,38 & $<0,0001$ & 0,0068 & 0,7745 \\
\hline
\end{tabular}


quantidade de amido poderia baixar o $\mathrm{pH}$ ruminal, reduzindo a digestibilidade da fibra da dieta.

Esse mesmo fenômeno poderia causar também o consumo de MS de concentrado ligeiramente menor observado neste grupo de animais. Paulino et al. (2003) discutiram esse tipo de resposta.

O aumento do coeficiente de digestibilidade da MS, MO e PB à medida que se aumentou o teor de PB da dieta como um todo, foi predito por Coelho da Silva \& Leão (1979). Segundo Van Soest (1994), esse efeito pode estar associado à diluição das perdas metabólicas fecais de proteína com o aumento do consumo de PB. Como o coeficiente de digestibilidade aparente é uma medida relativa, em baixos consumos de PB, essas perdas metabólicas têm maior capacidade de reduzir a estimativa do coeficiente de digestibilidade da PB, com reflexos sobre os coeficientes da MS e da MO.

O coeficiente de digestibilidade do EE e dos carboidratos não-fibrosos foi maior nos animais que recebiam suplemento concentrado $(\mathrm{P}<0,01)$. Devido à menor disponibilidade desses nutrientes no pasto, isto pode estar diretamente associado à maior digestibilidade dos mesmos nos concentrados.

O teor de NDT também foi maior na dieta dos animas sob suplementação com concentrados e aumentou linearmente com o nível de proteína na dieta $(\mathrm{P}<0,01)$. Como todos os grupos de animais sob suplementação apresentaram maior consumo de NDT em relação ao grupo controle e o aumento no teor de NDT dos grupos sob suplementação foi uniforme à medida que se aumentou o teor de proteína do concentrado, pode-se inferir que a substituição de parte do consumo de pasto por concentrado (de maior digestibilidade) e o aumento da digestibilidade ocasionado pelo maior teor de PB na dieta sejam igualmente responsáveis por esses resultados. Neste último aspecto, vale destacar que a questão levantada por Van Soest (1994) sobre a amplitude da interferência das perdas metabólicas fecais de proteína à medida que se aumenta a ingestão de PB também pode se refletir sobre a estimativa do NDT da dieta.
O pequeno tamanho e a pouca idade dos animais neste estudo tornam-se um fator naturalmente limitante a altas produções de proteína microbiana ruminal. Isso pode explicar a ausência de diferença na produção de proteína microbiana ruminal ( $P>0,10$, Tabela 5) entre os animaisreferência e aqueles sob suplementação, e mesmo entre os níveis de proteína no concentrado.

A consequência direta disso é a baixa eficiência de produção de proteína microbiana ruminal quando considerada a ingestão diária de NDT. Este resultado indica alta variabilidade no padrão de produção de $130 \mathrm{~g}$ PBmic/kg NDT adotado pelo NRC (2000), já assumida por este conselho ao definir este padrão. Fatores como idade e estágio fisiológico dos animais, além de suprimento inadequado de PDR na dieta, podem afetar diretamente a eficiência de síntese dos microrganismos ruminais.

Os níveis séricos de nitrogênio da ureia não diferiram significativamente entre os animais que recebiam ou não concentrados $(\mathrm{P}>0,10)$. Como a ingestão de $\mathrm{PB}$ diferiu entre esses grupos, a semelhança do nitrogêncio da ureia sérica pode ser atribuída às diferenças na eficiência de uso desta PB pelo metabolismo dos animais.

Uma vez que os animais sob suplementação ingeriram mais PB em relação aos do grupo controle, níveis semelhantes de ureia sérica poderiam ser produzidos por melhor uso da proteína bruta absorvida pelos últimos. Como a ingestão de PB de pasto dos animais controle foi maior que naqueles sob suplementação, e a superioridade destes últimos na ingestão de PB está relacionada ao consumo de $\mathrm{PB}$ do concentrado, pode-se elencar duas hipóteses para explicar esta diferença no uso da PB absorvida.

Inicialmente, pode-se considerar que maior degradabilidade ruminal da PB ingerida a partir do pasto, sem que os microrganismos ruminais sejam capazes de aproveitar toda a amônia liberada na degradação desta $\mathrm{PB}$, levaria à maior produção de ureia no fígado, a qual seria excretada, elevando-se os níveis plasmáticos de ureia. Outra possibilidade seria um melhor balanceamento

Tabela 5 - Parâmetros da nutrição proteica dos animais experimentais

\begin{tabular}{|c|c|c|c|c|c|c|c|c|}
\hline & \multicolumn{4}{|c|}{ Suplemento } & \multirow{3}{*}{$\begin{array}{l}\mathrm{CV} \\
(\%)\end{array}$} & \multicolumn{3}{|c|}{ Valor-P } \\
\hline & \multirow[t]{2}{*}{ Controle } & \multicolumn{3}{|c|}{$\begin{array}{l}\text { Nível de proteína } \\
\text { no concentrado }\end{array}$} & & \multirow{2}{*}{$\begin{array}{c}\text { Efeito da } \\
\text { suplementação } \\
\text { concentrada }\end{array}$} & \multirow{2}{*}{$\begin{array}{l}\text { Efeito linear } \\
\text { do nível } \\
\text { de proteína }\end{array}$} & \multirow{2}{*}{$\begin{array}{c}\text { Efeito } \\
\text { quadrático do níve } \\
\text { de proteína }\end{array}$} \\
\hline & & Baixo & Médio & Alto & & & & \\
\hline Produção de $N$ microbiano (g/dia) & 39,4 & 45,4 & 46,6 & 37,1 & 44,2 & 0,3663 & 0,6708 & 0,7014 \\
\hline $\begin{array}{l}\text { Eficiência de síntese de proteína } \\
\text { bruta microbiana (g/kg NDT) }\end{array}$ & 96,7 & 106 & 91,0 & 81,5 & 47,5 & 0,8327 & 0,2988 & 0,8844 \\
\hline N da ureia sérica (mg/dL) & 11,7 & 9,66 & 11,0 & 16,4 & 38,6 & 0,6484 & 0,0008 & 0,2226 \\
\hline \multicolumn{9}{|l|}{ Excreção urinária de $\mathrm{N}$} \\
\hline Na forma de ureia (g/dia) & 26,8 & 28,9 & 25,4 & 34,9 & 49,8 & 0,5427 & 0,3579 & 0,2844 \\
\hline Total (g/dia) & 30,8 & 37,5 & 34,7 & 42,0 & 43,6 & 0,1723 & 0,5227 & 0,4318 \\
\hline
\end{tabular}


dos aminoácidos da PNDR dos concentrados em relação ao pasto. Como a produção de proteína microbiana ruminal foi semelhante entre os grupos, pode-se supor que as diferenças no aporte de aminoácidos absorvidos no intestino delgado estariam ligadas às diferenças de consumo e à composição de aminoácidos da PNDR do pasto e dos concentrados. Caso a composição de aminoácidos do pasto fosse mais desbalanceada que a dos concentrados, uma maior porcentagem dos aminoácidos oriundos do pasto seriam deaminados no fígado, gerando maior produção de ureia neste órgão. Como o consumo de PB oriunda do pasto dos animais controle foi maior que o daqueles sob suplementação, apesar destes últimos ingerirem mais PB no dia (boa parte oriunda dos concentrados), a quantidade diária de aminoácidos deaminados no fígado foi semelhante entre os grupos, assim como a produção de ureia por este órgão.

Entre os animais que recebiam suplemento concentrado, os níveis séricos de nitrogênio da ureia aumentaram linearmente com o aumento do teor de PB no concentrado $(\mathrm{P}<0,01)$. Esse resultado acompanhou o comportamento da ingestão de PB desses grupos de animais, podendo ser associado diretamente à quantidade de proteína disponível para metabolização pelos animais (Valadares et al., 1997). A análise da excreção diária de nitrogênio pela urina não mostrou efeito de suplementação ou do nível de proteína no concentrado.

Quanto aos animais sob suplementação, não só a quantidade de PB ingerida, mas também a velocidade de ingestão de suplemento, pode afetar a eficiência de utilização desta proteína no fígado e a produção e secreção de ureia por este órgão. O rápido consumo de proteína dificulta seu aproveitamento pelo metabolismo, aumentando a excreção urinária de nitrogênio. Isso pode ser responsável pelos mais baixos valores de excreção urinária de nitrogênio nos animais que recebiam o suplemento concentrado de média proteína.

\section{Conclusões}

O consumo de concentrado substitui parte do pasto ingerido pelos bezerros, melhorando a digestibilidade da dieta e o aproveitamento metabólico da proteína. O nível de proteína no suplemento afeta linear e positivamente a digestibilidade da dieta.

\section{Referências}

BRITO, R.M.; SAMPAIO, A.A.M. Técnicas de suplementação de pastagens na criação de bezerros de corte: creepfeeding. Jaboticabal: FUNEP, 2001.126p.
BRITO, R.M.; SAMPAIO, A.A.M.; CRUZ, G.M. et al. Comparação de sistemas de avaliação de dietas para bovinos no modelo de produção intensiva de carne. II - Creep feeding. Revista Brasileira de Zootecnia, v.31, n.2, p.1002-1010, 2002 (supl.).

BÜRGER, P.J.; PEREIRA, J.C.; COELHO DA SILVA, J.F. et al. Consumo e digestibilidade aparente total e parcial em bezerros holandeses alimentados com dietas contendo diferentes níveis de concentrado. Revista Brasileira de Zootecnia, v.29, n.1, p.206-214, 2000.

CASALI, A.O.; DETMANN; E.; VALADARES FILHO, S.C. et al. Influência do tempo de incubação e do tamanho de partículas sobre os teores de compostos indigestíveis em alimentos e fezes bovinas obtidos por procedimentos in situ. Revista Brasileira de Zootecnia, v.37, n.2, p.335-342, 2008.

CHEN, X.B.; GOMES, M.J. Estimation of microbial protein supply to sheep and cattle based on urinary excretion of purine derivatives - an overview of technical details (Occasional publication). International Feed Resources Unit. Bucksburnd, Aberdeen: Rowett Research Institute, 1992. 21p.

CHIZZOTTI, M.L.; VALADARES FILHO, S.C.; VALADARES, R.F.D. et al. Excreção de creatinina em novilhos e novilhas. In: REUNIÃO ANUAL DA SOCIEDADE BRASILEIRA DE ZOOTECNIA, 41., 2004, Campo Grande. Anais... Campo Grande: Sociedade Brasileira de Zootecnia, 2004. (CD-ROM).

COCHRAN, R.C.; ADAMS, D.C.; WALLACE, J.D. et al. Predicting digestibility of different diets with internal markers: Evaluation of four potential markers. Journal of Animal Science, v.63, n.5, p.1476-1483, 1986.

COELHO DA SILVA, J.F.; LEÃO, M.I. Fundamentos da nutrição de ruminantes. Piracicaba: Livroceres, 1979. 384p.

EUCLIDES, V.P.B.; MACEDO, M.C.M.; OLIVEIRA, M.P. Avaliação de diferentes métodos de amostragem (para se estimar o valor nutritivo de forragens) sob pastejo. Revista Brasileira de Zootecnia, v.21, n.2, p.691-702, 1992.

FREITAS, J.A.F.; QUEIROZ, A.C.; DUTRA, A.R. et al. Composição do ganho e exigências de energia e proteína para ganho de peso em bovinos Nelore puros e mestiços. Revista Brasileira de Zootecnia, v.35, n.3, p.886-893, 2006.

KINCHELOE, J.J. Variation in supplement intake by grazing beef cows. 2004. 72f. Thesis (Master of Science in Animal and Range Sciences) - Montana State University, Bozeman, Montana.

LICITRA, G.; HERNANDES, T.M.; VAN SOEST, P.J. Standardizations of procedures for nitrogen fractionation of ruminant's feeds. Animal Feed Science and Technology, v.57, p.347-358, 1996.

MCMENIMAN, N.P. Methods of estimating intake of grazing animals. In: Reunião Anual da Sociedade Brasileira de Zootecnia, 34. 1997, Juiz de Fora. Anais... Juiz de Fora: SBZ, 1997. p.131-168.

NATIONAL RESEARCH COUNCIL - NRC. Nutrient requirements of beef cattle. 7.ed. Washington, D.C.: National Academy Press, 2000. 243p.

PAULINO, M.F.; ACEDO, T.S; SALES, M.F.L. et al. Suplementação como estratégia de manejo das pastagens. In: REIS, R.A.; BERNARDES, T.F.; SIQUEIRA, G.R. (Orgs.) Volumosos na produção de ruminantes: valor alimentício de forragens. Jaboticabal, 2003. p.87-100.

RESTLE, J.; PACHECO, P.S.; MOLETTA, J.L. et al. Grupo genético e nível de nutricional pós-parto na produção e composição do leite de vacas de corte. Revista Brasileira de Zootecnia, v.32, n.3, p.585-597, 2003.

RIBEIRO, T.R.; PEREIRA, J.C.; OLIVEIRA, M.V.M. et al. Influência do plano nutricional sobre o desempenho de bezerros holandeses para produção de vitelos. Revista Brasileira de Zootecnia, v.30, n.6, p.2145-2153, 2001 (Supl.).

RODRÍGUEZ, N.M.; SIMÕES SALIBA, E.O.; GUIMARÃES JUNIOR, R. Uso de indicadores para estimativa de consumo a pasto e digestibilidade. In: REUNIÃO ANUAL DA SOCIEDADE BRASILEIRA DE ZOOTECNIA, 43., 2006, João Pessoa. Anais... João Pessoa: Sociedade Brasileira de Zootecnia, 2006. p.323-352. 
SILVA, D.J.; QUEIROZ, A.C. Análise de alimentos (métodos químicos e biológicos). Viçosa, MG: Universidade Federal de Viçosa, 2002. 235p

SILVA, F.F.; VALADARES FILHO, S.C.; ÍTAVO, L.C.V. et al. Composição corporal e requisitos energéticos e protéicos de Nelore, não-castrados, alimentados com rações contendo diferentes níveis de concentrado e proteína. Revista Brasileira de Zootecnia, v.31, n.1, p.503-513, 2002 (supl. 1).

SteEL, R.G.D.; TORRIE, J.H.; DICKEY, D.A. Principles and procedures of statistics. A biometrical approach. 3.ed. New York: McGraw Hill Co., 1997. 666p.

VALADARES, R.F.D.; GONÇALVES, L.C.; RODRIGUEZ, N.M. et al. Níveis de proteína em dietas de bovino. 4. Concentrações de amônia ruminal e uréia plasmática e excreções de uréia e creatinina. Revista Brasileira de Zootecnia, v.26, n.6, p.1270-1278, 1997.

VALADARES, R.F.D.; BRODERICK, G.A.; VALADARES FILHO, S.C. et al. Effect of replacing alfalfa silage with high moisture corn on ruminal protein synthesis estimated from excretion of total purine derivatives. Journal of Dairy Science, v.82, n.11, p.2686-2696, 1999.

VAN SOEST, P.J.; ROBERTSON, J.B. Analysis of forages and fibrous foods. Ithaca: Cornell University, 1985. 202p.

VAN SOEST, P.J. Nutritional ecology of the ruminant. 2.ed. Ithaca: Cornell University, 1994. 476p.

VERBIC, J.; CHEN, X.B.; MACLEOD, N.A. et al. Excretion of purine derivatives by ruminants. Effects of microbial nucleic acid infusion on purine derivative excretion by steers. Journal of Agricultural Science, v.114, n.3, p.243-248, 1990.

ZAMPERLINI, B. Concentração de proteína e cronologia de fornecimento de suplementos para bezerros lactentes sob sistema de creep feeding. 2008. 68f. Tese (Doutorado em Zootecnia) - Universidade Federal de Viçosa, Viçosa, MG.

ZIN, R.A.; GARCES, P. Suplementação de bovinos de corte a pasto: considerações biológicas e econômicas. In: SIMCORTE - SIMPÓSIO INTERNACIONAL DE PRODUÇÃO DE GADO DE CORTE, 1., 2006, Viçosa, MG. Anais... Viçosa, MG: DZO/ UFV, 2006. p.15-30. 